\title{
Viewpoint
}

\section{Is chronic synovitis an example of reperfusion injury?}

\author{
T WOODRUFF, ${ }^{1}$ D R BLAKE, ${ }^{1}$ J FREEMAN ${ }^{2}$ F J ANDREWS, ${ }^{1}$ P SALT, ${ }^{2}$ \\ AND J LUNEC
}

From the Departments of ${ }^{\prime}$ Rheumatology and ${ }^{2}$ Anaesthetics, The Medical School, University of Birmingham

SUMMARY In an attempt to define why the joint synovial cavity is prone to develop persistent synovial inflammation we show that hypoxia is induced by pressure changes caused by exercise in the presence of an inflammatory effusion. On resting 'reperfusion injury' may take place. The biochemistry of reperfusion injury has only recently been defined and perhaps surprisingly for an insult that has hypoxia as its central ingredient involves the subsequent production of oxygen derived free radical species. ${ }^{1}$ We apply the reaction sequences that are believed to occur during hypoxic/reperfusion injury to the joint synovial cavity and, on the basis of reported 'in vivo' observations, suggest novel therapeutic approaches that we believe are applicable to the treatment of persistent synovial inflammation.

One of the current theories for tissue damage in chronic inflammatory polyarthritis involves the production of oxygen derived free radicals from neutrophils and macrophages and subsequent radical induced tissue damage. We and others have previously suggested that the hydroxyl radical is potentially the most toxic of the oxygen radical species, and its formation is dependent upon the presence of suitable transition metal catalysts. ${ }^{1-3}$ Such catalysts are present in inflammatory synovial fluid. ${ }^{4}$ Clearly another essential ingredient for oxygen radical injury is sufficient concentration of oxygen to support free radical production. It has recently been suggested that production of oxygen radicals during inflammation may be limited by oxygen concentration. ${ }^{5}$ In rat polymorphonuclear leucocytes the oxygen concentration that gave $50 \%$ of the maximum stimulated oxygen radical production was between 20 and $30 \mu \mathrm{mol} / \mathrm{l}$ depending on the stimulus used to induce the respiratory burst. The oxygen tension in arthritic joints has been measured by a variety of research groups, and results vary from as low as $0 \mathrm{mmHg}$ up to $90 \mathrm{mmHg} .^{6-9}$ In general, inflammatory effusions had lower oxygen tensions than non-inflammatory effusions and the more

Accepted for publication 3 March 1986.

Correspondence to Dr D R Blake, Department of Rheumatology, The Medical School. University of Birmingham, B15 2TJ. severe histological grading of synovial changes correlated with lower oxygen tensions.

One of the determinants of the oxygen tension in synovial fluid is the blood supply to the synovium, which we presume must be related to pressure inside the joint. Pressures of up to $800 \mathrm{mmHg}$ have been noted during quadriceps setting in rheumatoid knees. ${ }^{10}$ During walking, in the presence of a $40 \mathrm{ml}$ effusion, pressures ranged from 10 to $20 \mathrm{mmHg}$ and up to $250 \mathrm{mmHg}$ during foot stance, and even with a $5 \mathrm{ml}$ effusion peak pressure was greater than 60 $\mathrm{mmHg}$. The hydrostatic pressure in normal capillaries is about $30 \mathrm{mmHg}$ and can increase to 60 $\mathrm{mmHg}$ in inflamed tissue. It is clear that in the process of walking the rheumatoid synovium is potentially quite ischaemic and therefore hypoxic, albeit temporarily.

Perhaps surprisingly, temporary ischaemic tissue injury with hypoxia is thought to be partly mediated $\mathrm{N}$ by oxygen derived free radicals. ${ }^{11}$ The protective $\omega$ effect of various free radical scavengers on ischaemia induced injury has been well demon- $\varrho$ strated in a variety of tissues. ${ }^{12-14}$ Intestinal $\Phi^{\infty}$ ischaemia in cats, as measured by increase in vascular permeability, can be substantially reduced by pretreatment with superoxide dismutase, but not $\frac{}{\mathbb{D}}$ by pretreatment with antihistamines, indomethacin, $\frac{\rho}{\mathbb{Q}}$ or methylprednisolone. ${ }^{12}$ The effect of ischaemia on $\propto$ myocardial function in various animals has been 
modified by treatment with superoxide dismutase, catalase, and mannitol, all putative scavengers of oxygen metabolites. ${ }^{13}$ is 16 Ischaemic skin flaps in rats can be protected from necrosis by pretreatment with superoxide dismutase before the reperfusion phase. ${ }^{14}$

A well described free radical generating system in vitro is the xanthine/xanthine oxidase system. The mechanism of production of free radicals in this system is thought to be as follows:

$$
\begin{gathered}
\text { xanthine } \\
\text { oxidase } \\
\text { xanthine }+\mathrm{H}_{2} 0+2 \mathrm{O}_{2} \rightarrow \text { uric acid }+20 \overline{2}+2 \mathrm{H}^{+}
\end{gathered}
$$

In the presence of transition metals superoxide radical can then be converted to the hydroxyl radical.

$$
\begin{gathered}
2 \mathrm{O}_{2}+2 \mathrm{H}^{+} \longrightarrow \mathrm{O}_{2}+\mathrm{H}_{2} \mathrm{O}_{2} \text { (dismutase reaction) } \\
0_{2}+\mathrm{Fe}^{3+} \longrightarrow \mathrm{Fe}^{2+}+\mathrm{O}_{2} \text { (ferric iron reduction) } \\
\mathrm{Fe}^{2+}+\mathrm{H}_{2} \mathrm{O}_{2} \rightarrow \mathrm{Fe}^{3+}+0 \mathrm{H}+\mathrm{OH}^{-} \text {(hydroxyl radical } \\
\text { formation) }
\end{gathered}
$$

Xanthine oxidase occurs in two forms, type D (dehydrogenase) and type $\mathrm{O}$ (oxidase). In most healthy tissues it is present as type D and catalyses the following reaction:

$$
\begin{gathered}
\text { xanthine } \\
\text { dehydrogenase }
\end{gathered} \text { uric acid }+\mathrm{NADH}+\mathrm{H}^{+}
$$

During ischaemia, however, it is converted to type $\mathrm{O}$, either by a calcium dependent protease or by thiol group modification, and it is this form which catalyses the superoxide producing reaction (equation 1). ${ }^{17-19}$ Ischaemia also results in a fall in cellular adenosine triphosphate concentrations as it is converted to xanthine and hypoxanthine. On reperfusion oxygen is supplied and acts as the electron receptor in place of $\mathrm{NAD}^{+}$, and superoxide is formed. In addition to the protective effects of free radical scavengers on ischaemic induced injury, all of the above models may also be protected by pretreatment with allopurinol, a xanthine oxidase inhibitor and potential hydroxyl radical scavenger. ${ }^{20-23}$ Post-transplantation renal function in dogs can also be improved by pretreatment of the kidney with allopurinol. ${ }^{24} 25$

Although inflammatory arthritis is associated with lower synovial fluid oxygen tensions and exercise causes marked pressure changes in the presence of an effusion, the relation between exercise and oxygen tension has not been explored in detail. Lund-Olesen $e t$ al reported three of four joints, aspirated before and after exercise, to have a fall in synovial fluid oxygen tension after exercise. ${ }^{6}$ To confirm and extend these observations we have looked at seven patients who, with a pressure tranducer in the knee joint, were asked to perform non-weight bearing isometric quadriceps setting. All patients generated pressures greater than $60 \mathrm{mmHg}$ during exercise, and five of seven patients had a fall in the synovial fluid oxygen tension postexercise of $15-30 \mathrm{~mm} \mathrm{Hg}$. Within 20 minutes the oxygen tension had risen and exceeded the pre-exercise value by $5-30 \mathrm{mmHg}$.

With such fluctuations in oxygen tension it is possible that the above mechanism postulated for ischaemia induced injury in other tissues ${ }^{1}$ is applicable to the inflamed synovium. We suggest that continued fluctuations in oxygen tension occur with moderate daily activities and that subsequent sustained free radical production is an important factor in persistent synovial inflammation. In support of this concept there are several clinical observations which may be compatible with such a mechanism. Firstly, the beneficial effect of prolonged bed rest in many patients with persistent synovitis may be attributable to a marked reduction in oxygen tension fluctuations. On the other hand, the apparently contrasting effect of overnight rest producing early morning stiffness may be due to reperfusion and persistent free radical production which resolves with either exercise, which may decrease free radical production by producing hypoxia, or by continued rest, which gradually leads to a more stable environment and therefore decreases free radical production.

A mechanism for the perpetuation of synovitis is therefore suggested (Fig. 1) based on this hypoxia/ reperfusion hypothesis, ${ }^{\top}$ and sites for novel potential therapeutic intervention are indicated. It has already been shown that desferrioxamine, an iron chelating agent, can decrease the severity of synovitis in animal models (Fig. 1e). ${ }^{26}$ Toxicity, however, limits its use. ${ }^{27}$ Reagents containing thiol groups may interfere with the xanthine dehydrogenase/ oxidase conversion and in that respect it is worth noting that gold compounds and D-penicillamine contain thiol groups (Fig. 1a). Free radical scavenging with superoxide dismutase has already been shown to be of benefit in adjuvant and collagen induced arthritis (Fig. 1f). If the dehydrogenaseoxidase conversion in vivo is dependent on calcium dependent protease rather than on a thiol oxidation reaction then interference with calcium fluxes may be a therapeutic alternative (Fig. 1b). Classic calcium channel blockers such as verapamil and nifedipine have been shown in the rat foot oedema model to have an anti-inflammatory effect. ${ }^{28}$ In addition, non-steroidal anti-inflammatory agents have been shown to release membrane bound stores of calcium from rabbit peritoneal polymorphonu- 


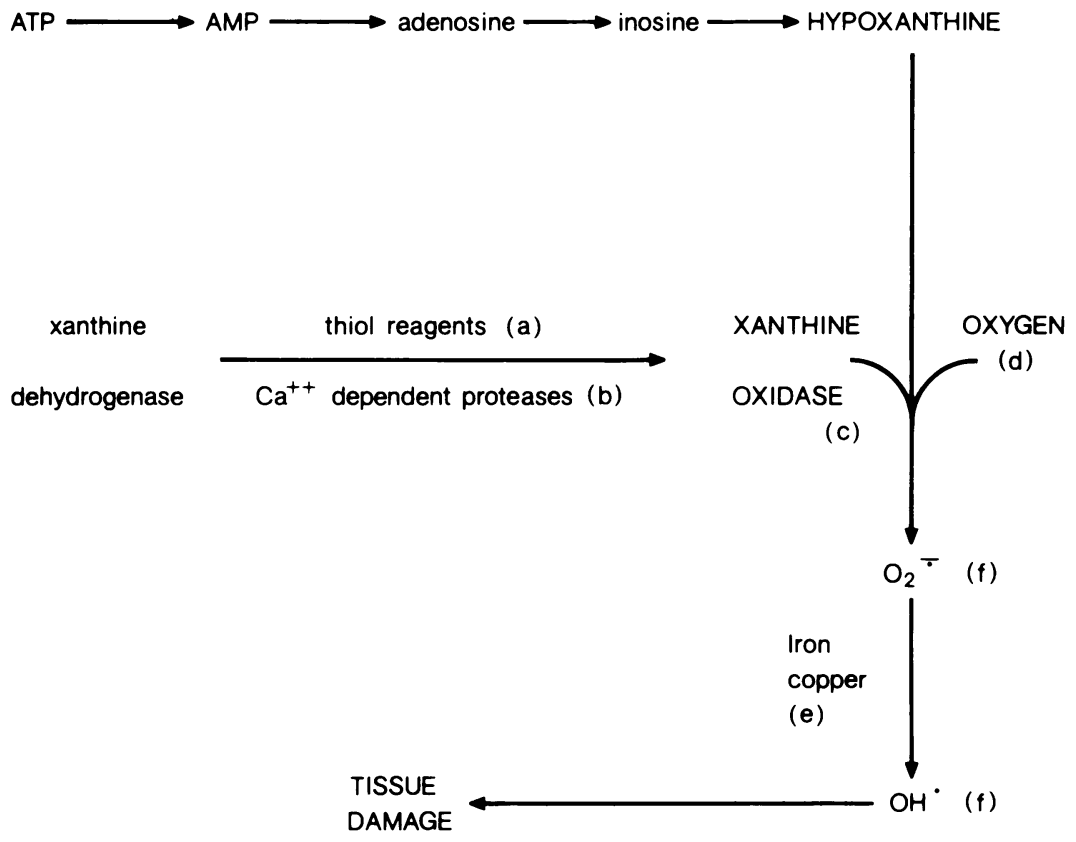

Fig. 1 Letters indicate potential sites for therapeutic intervention. (After McCord et al.')

clear leucocytes, and it is possible that this is another pharmacological mode of action of these agents. ${ }^{29}$ Finally, inhibition of xanthine oxidase by allopurinol or other xanthine oxidase inhibitors (Fig. 1c) is a further potential method of intervention either alone or in combination with other agents directed at different stages of the reaction sequence.

In summary, oxygen derived free radicals, which are thought to play a part in tissue damage in chronic inflammation, may be produced by recurrent reperfusion injury in joints subjected to repeated pressure changes. We believe that this may be a mechanism for the persistence of synovial inflammation and an explanation for its improvement with rest. A variety of potential therapeutic options are explored in relation to this hypothesis, including free radical scavengers, thiol reagents, calcium channel blockers, and xanthine oxidase inhibitors.

At the Eular Rhcuma Symposium (Osto 1983) Dr W Dawson (Eli Lilly UK) requested rheumatologists to provide the clinical observations that might form the basis for novel approaches for treating synovial inflammation. We acknowledge this request and Dr J McCord's original observations as the stimulus for this paper. We are grateful to Dr B Halliwell for his helpful comments.

\section{References}

1 McCord J M. Oxygen derived free radicals in post ischaemic $\mathrm{O}$ tissuc injury. $N$ Engl J Med 1985: 312: 159-63.

2 Blake D R. Hall N D, Bacon P A. Dieppe P A. Halliwell B, Gutteridge $J$ M C. The importance of iron in rhcumatoid discase. Lancet 1981; ii: 1142-4.

3 Halliwell B. Gutteridge J M C. Oxygen toxicity, oxygen O radicals. transition metals and discasc. Biochem J 1984: 219: N $1-14$.

4 Rowley D A. Gutteridge J M C. Blake D. Farr M. Halliwell B. Lipid peroxidation in rhcumatoid arthritis. Thiobarbituric $\underset{\gamma}{ }$ acid-reactive material and catalytic iron salts in synovial fluid from rhcumatoid patients. Clin Sci 1984: 66: 691-5.

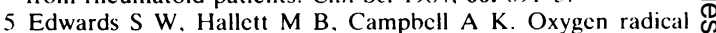
production during inflammation may be limited by oxygen? concentration. Biochem J 1984; 217: 851-4.

6 Lund-Olesen K. Oxygen tension in synovial fluids. Arthritis Rheum 1970; 13: 769-76.

7 Falchuk K H. Goetzl E J, Kulka N P. Respiratory gases of synovial fluids. Am J Med 1970): 49: 223-31.

8 Treuhaft P S, McCarty D J. Synovial fluid pH, lactate, oxygen 
and carbon dioxide partial pressure in various joint discases. Arthritis Rheum 1971: 14: 475-84.

9 Richman A I. Su E Y. Ho G. Reciprocal relationship of synovial fluid volume and oxygen tension. Arthritis Rheum 1981: 24: 701-5.

10 Jayson M I. Dixon A St J. Intra-articular pressure in rheumatoid arthritis of the knee (I. II. III). Ann Rheum Dis 1970; 29: 261-8, 401-8.

11 Meerson F Z, Kagan V E. Kozlov í P. Belkina L M, Arkhipenko $Y \mathrm{~V}$. The role of lipid peroxidation in pathogenesis of ischaemic damage and the antioxidant protection of the heart. Basic Res Cardiol 1982: 77: 465-85.

12 Granger D N. Rutili G. McCord J M. Superoxide radicals in feline intestinal ischacmia. Gastroenterology 1981; 81: 22-9.

13 Shlafer M. Kane P F. Kirsh M M. Supcroxide dismutase plus catalase enhance the efficacy of hypothermic cardioplegia to protect the globally ischacmic, reperfused heart. $J$ Thorac Cardiovasc Surg 1982: 83: 830-9.

14 Manson P N, Anthenelli R M. Im M J. Bulkley G B. Hoopes $J E$. The role of oxygen-frec radicals in ischacmic tissuc injury in island skin flaps. Ann Surg 1983: 198: 87-90.

15 Shlafer M. Kane P F. Wiggins V Y. Kirsh M M. Possible role for cytotoxic oxygen metabolites in the pathogenesis of cardiac ischemic injury. Circulation 1982; 66 (suppl 2): I85-92.

16 Stcwart J R. Blackwcll W H, Crutc S L. Loughlin V. Hess M L, Greenficld L J. Prevention of myocardial ischaemia/reperfusion injury with oxygen frec-radical scavengers. Surg Forum 1982; 33: $317-20$.

17 Battelli M G. Della Cortc E. Stirpc F. Xanthinc oxidase typc D (dehydrogenase) in the intestinc and other organs of the rat. Biochem J 1972: 126: 747-9.

18 Della Corte E. Stirpe F. The regulation of rat liver xanthine oxidase: involvement of thiol groups in the conversion of the cnzyme activity from dehydrogenase (typc D) into oxidase (typc O) and purification of the cnzymc. Biochem J 1972; 126: $739-45$.
19 Roy R S. McCord J M. Ischacmia induced conversion of xanthine dehydrogenase to xanthine oxidase [Abstract]. Fed Proc 1982; 41: 757: 2900.

20 Parks D A. Bulklev G B, Granger D N. Role of oxygen-derived frec radicals in digestive tract discases. Surgery 1983: 94: 415-22.

21 Chambers D E. Parkes D A. Patterson G, et al. Xanthine oxidase as a source of frec radical damage in myocardial ischaemia. J Mol Cell Cardiol 1985: 17: 145-52.

22 Im M J, Shen W-H, Pak C J, Manson P N, Bulkley G B, Hoopes J E. Effect of allopurinol on the survival of hyperemic island skin flaps. Plast Reconstr Surg 1984; 73: 276-8.

23 Halliwell B. Gutteridge J M C. The importance of free radicals and catalytic metal ions in human diseases. Mol Aspects Med 1985; 8: 89-193.

24 Owens M L. Lazarus H M. Wolcott M W. Maxwell J G. Taylor B. Allopurinol and hypoxanthine pretreatment of canine kidney donors. Transplantation 1974; 17: 424-7.

25 Toledo-Percyra L H. Simmons R L, Najarian J S. Effect of allopurinol on the preservation of ischaemic kidneys perfused with plasma or plasma substitutes. Ann Surg 1974; 180: 780-2.

26 Blake D R. Hall N D. Bacon P A. Dieppe P A, Halliwell B, Gutteridge $J$ M C. Effect of a specific iron chelating agent on animal models of inflammation. Ann Rheum Dis 1983; 42: 89-93.

27 Blake D R, Winyard P. Lunec J. et al. Cerebral and ocular toxicity induced by desferrioxaminc. $Q J$ Med 1985; 219: 345-55.

28 Bonnet J, Loiscau A M. Orvoen M. Bessin P. Plateletactivating factor acether (PAF-acether) involvement in acute inflammatory and pain processes. Agents Actions 1981: 11: 559-62.

29 Northover A M, Northover B J. Calcium ions in acute inflammation. In: Bonti I L, Bray M A, Parnham M J, eds. The pharmacology of inflammation. Amsterdam: Elsevier, 1984: 240. 